\title{
Allometric relationships among body mass, MUZZLE-tail length, and tibia length during the growth of Wistar rats ${ }^{1}$
}

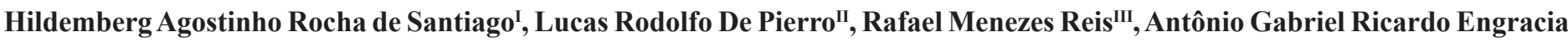 \\ Caluz $^{\text {IV }}$, Victor Barbosa Ribeiro"I, José Batista Volpon ${ }^{\mathrm{V}}$
}

DOI: http://dx.doi.org/10.1590/S0102-865020150110000004

IFellow PhD degree, Postgraduate Program in Health Sciences Applied to the Locomotor System, Faculty of Medicine of Ribeirao Preto, Universidade de Sao Paulo (USP), Ribeirao Preto-SP, Brazil. Design, intellectual and scientific content of the study; technical procedures; acquisition and interpretation of data; manuscript writing.

II Graduate student, Physical Therapy Course, Faculty of Medicine of Ribeirao Preto, USP, Ribeirao Preto-SP, Brazil. Acquisition and interpretation of data, technical procedures.

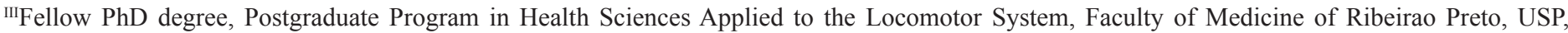
Ribeirao Preto-SP, Brazil. Department of Internal Medicine, Division of Radiology. Allometry calculation and interpretation of data, statistical analysis, manuscript preparation.

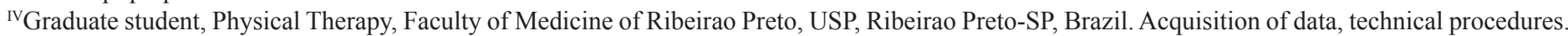
${ }^{v}$ PhD, Full Professor, Faculty of Medicine of Ribeirao Preto, USP, Ribeirao Preto-SP, Brazil. Design, intellectual and scientific content of the study; manuscript writing; critical revision; final approval.

\section{ABSTRACT}

PURPOSE: To investigate allometric relationships among body mass (BM), muzzle-tail length (MTL), and tibia length (TL) in Wistar rats and establish their growth rate change parameters.

METHODS: Eighteen male and 18 female Wistar rats were studied from the 3rd to the 21st week of age. BM, MTL, and TL were measured daily, and relative growth was compared using allometry.

RESULTS: A positive correlation between BM and MTL $(p<0.05)$ and BM and TL $(p<0.05)$ was observed. Males and females showed comparable curves; however, females had turning points at a younger age. The allometric relationship between BM and MTL presented a regular increase until reaching a mass of $351 \mathrm{~g}$ (males) and $405 \mathrm{~g}$ (females). BM and TL showed an initial increase until $185 \mathrm{~g}$ (males) and $182 \mathrm{~g}$ (females), and then reached a plateau that finished at $412 \mathrm{~g}$ (males) and $334 \mathrm{~g}$ (females), to display another increase.

CONCLUSIONS: The allometric relationship of body mass with animal length and tibia length was comparable for male and female rats, with female rats maturing earlier. Animal longitudinal growth occurred in a single stage. In contrast, tibia length depicted two stages of accelerated growth with an intermediate period of deceleration.

Key words: Bone and Bones. Tibia. Body Weight. 


\section{Introduction}

Allometry is the scientific method for investigating the relationship between body size and shape, anatomy, physiology, and other growth parameters of several organs and body parts ${ }^{1-3}$. When allometric equations are applied to longitudinal studies by using body mass (BM) as a parameter in relation to the development of a specific organ or structure, it is possible to establish different growth curves and accurately indicate when growth rate changes occur. The method also allows for predicting the future size of an animal's particular structure at a specific age ${ }^{2}$. The most used linear models in allometry are based on the log-transformed equation suggested by Huxley ${ }^{1}$.

Experimental animal investigations allow tests and surgical interventions under controlled conditions, thus providing information that may be useful for planning human studies. The Wistar rat is an attractive animal model for both surgical and clinical research because of the good correspondence between rat and human anatomy, physiology, and behavior ${ }^{4}$. Moreover, the small size, short life cycle, and low breeding cost are additional advantages of this laboratory animal ${ }^{5}$.

Usually, BM is the most used parameter to confirm animal development and maturity, and it is adequate for most research purposes ${ }^{1}$. However, when studies are related to growth, it may be useful to know the developmental curve for a particular structure in relation to BM. In addition, organs and other anatomical structures do not develop independently, but maintain a relative proportion with $\mathrm{BM}$ increase that can be characterized by adequate mathematical treatment of data ${ }^{1}$.

The tibia of Wistar rats is one of the most used bones in orthopedic research ${ }^{6}$ because it is easily accessed and presents a standard morphology that is representative of a typical long bone. To the best of our knowledge, a detailed study of its growth in relation to BM increase has not yet been performed.

Thus, we aimed to study the relative growth between BM and body length and BM and TL in the Wistar rat.

\section{Methods}

This study was designed and conducted according to the National Research Council of the National Academies ${ }^{7}$, with approval by the Institutional Ethics Committee on Animal Experimentation (Protocol n. 0073/2015).

The animal house of the University provided mating animals (Rattus norvegicus albinus var. Wistar). During the experimental period, all animals had free access to tap water and chow (Nuvilab ${ }^{\circledR}$ CR-1, PR, Brazil). The rats were kept in standard cages with a solid floor and in a calm and controlled environment with 12-h light-dark periods, 55\% $( \pm 10)$ relative humidity, and $22^{\circ} \mathrm{C}( \pm 2)$ room temperature. Adequate bedding (wood shavings) was provided, with two changes per week. The study encompassed three stages: mating and pregnancy, offspring and breastfeeding, and follow-up after weaning.

\section{Mating and pregnancy}

Initially, nine young adult rats were used. Three breeding males and six primiparous matrices were mated to obtain enough offspring for selecting 36 pups (18 males and 18 females).

After reaching the reproductive age $(13 \text { weeks })^{5}$, matrices and breeding males were mated. The animals were maintained under temporary polygamous mating conditions with two females per male for up to two weeks. Copulation was confirmed by daily checking for the presence of sperm in the vaginal fluid collected with a cotton swab moistened with distilled water and introduced into the vagina. This material was smeared on a slide, without staining, and examined under a microscope to check for the presence of spermatozoa ${ }^{5}$. In positive cases, pregnancy was assumed, and the female was transferred to an individual cage. After pregnancy confirmation, the female was kept isolated from adult animals throughout the pregnancy and breastfeeding period.

\section{Offspring and breastfeeding}

After weighting newborn pups, the heaviest and more active animals from each litter were chosen to maintain a matrix of three males and three females, and this was followed from the $3^{\text {rd }}$ week to the $21^{\text {st }}$ week of post-natal life. The non-selected newborn animals were euthanized with a lethal dose of sodium thiopental administered intraperitoneally and discarded. The number of rat pups per litter was limited to achieve uniformity and avoid competition for breastfeeding. After weaning (three weeks of age), the pups were separated from the dam and kept in standard cages (three animals per cage). The matrices and breeding males were maintained for future matings, if necessary.

\section{Animal grouping and follow-up}

After proper management, the following groups were established:

Group I: 18 weanling male rats $(n=18)$ were followed up from three to 21 weeks of age.

Group II: weanling female rats $(n=18)$ were followed up from three to 21 weeks of age.

All evaluations were performed on a daily basis in the 
same period of the day to collect the following data: (a) BM was measured with an electronic scale (Mettler Toledo ${ }^{\mathrm{TM}}$, Brazil) with 1-g variation. (b) Muzzle-tail length (MTL): The awakened animal was gently restrained and placed in the prone position on a graphpaper-covered flat surface. Gentle traction was applied between the tip of the tail and the head. Then, the muzzle-tip tail distance was measured by markings made on the graph paper. (c) Tibia length (TL): A digital caliper (Mitutoyo ${ }^{\mathrm{TM}}$, Brazil) was used to measure the distance between the medial interarticular line of the knee (perceived by a depression on palpation) and the end of the medial malleolus in the right tibia.

After completion of the follow-up period, the animals were maintained for use in other experiments.

\section{Allometric calculation}

Allometric calculation was based on the logtransformed model established by Huxley ${ }^{1}$. It takes into account the parabola equation $y=b X^{\alpha}$, wherein " $y$ " is the dependent variable (animal length or tibia length), " $X$ " is the independent variable (body mass), " $b$ " is the initial growth coefficient, and " $\alpha$ " is the angular coefficient, also known as the coefficient of allometry ${ }^{9}$ (Gayon). Therefore, $\operatorname{Ln} y=\operatorname{Ln} b+\alpha \operatorname{Ln} X$.

\section{Statistical analysis}

The Shapiro-Wilk test was used to check for data normality. The Mann-Whitney test was used to compare BW, MTL, and TL values between males and females. Linear regression was used between BW and MTL values and between BW and TL values to calculate the " $a$ " and " $b$ " coefficients in Huxley's equation. Spearman's correlation was used between the actual MTL and TL values and those obtained by the aforementioned equation. The significance level was $5 \%(\mathrm{p} \leq 0.05)$. SPSS, version 20 (IBM, Armonk, New York, USA) and GraphPad Prism, version 5 (GraphPad Software, San Diego, USA) were used to conduct all analyses.

\section{Results}

On average, the matrices produced litters with 9-15 pups $($ mean $=11.6 \pm 2.1)$. There were two stillborns, and the mean body mass was $6.5 \mathrm{~g}( \pm 2.12 \mathrm{~g})$.

BW, MTL, and TL mean values are shown in Table 1 for males and in Table 2 for females. The mean values of the studied parameters were significantly higher for males than for females (BM: $\mathrm{p}<0.0001$, MTL: $\mathrm{p}=0.04$, and TL: $\mathrm{p}=0.03$ ).

TABLE 1 - Mean body mass (BM), muzzle - tail length (MTL), and tibia length (TL), with respective errors (SEM) and standard deviations (SD) of male Wistar rats according to the post-natal age.

\begin{tabular}{|c|c|c|c|c|c|c|c|c|c|}
\hline \multirow[t]{2}{*}{ Age (weeks) } & \multicolumn{3}{|c|}{ BM (g) } & \multicolumn{3}{|c|}{ MTL (cm) } & \multicolumn{3}{|c|}{$\mathrm{TL}(\mathrm{cm}$} \\
\hline & Mean & SD & SEM & Mean & $\mathrm{SD}$ & SEM & Mean & $\mathrm{SD}$ & SEM \\
\hline 3 & 78.25 & 19.09 & 7.792 & 22.86 & 2.49 & 1.01 & 2.36 & 0.12 & 0.05 \\
\hline 4 & 140.6 & 17.58 & 7.17 & 29.30 & 1.83 & 0.74 & 2.66 & 0.18 & 0.07 \\
\hline 5 & 209.9 & 27.73 & 10.48 & 34.93 & 1.81 & 0.68 & 2.86 & 0.08 & 0.03 \\
\hline 6 & 281.9 & 17.46 & 7.80 & 39.88 & 1.36 & 0.61 & 3.07 & 0.07 & 0.03 \\
\hline 7 & 330.7 & 22.54 & 10.08 & 42.74 & 0.88 & 0.39 & 2.94 & 0.03 & 0.01 \\
\hline 8 & 375.1 & 8.81 & 3.59 & 44.54 & 1.31 & 0.53 & 3.08 & 0.18 & 0.07 \\
\hline 9 & 437.7 & 26.30 & 15.18 & 46.86 & 0.85 & 0.49 & 3.23 & 0.05 & 0.03 \\
\hline 10 & 508.7 & 7.21 & 3.60 & 49.08 & 0.62 & 0.31 & 3.35 & 0.03 & 0.01 \\
\hline 11 & 531.7 & 9.12 & 5.26 & 49.83 & 0.56 & 0.32 & 3.39 & 0.07 & 0.04 \\
\hline 12 & 546.7 & 9.05 & 4.52 & 50.51 & 0.44 & 0.22 & 3.44 & 0.05 & 0.02 \\
\hline 13 & 569.5 & 2.69 & 1.55 & 49.68 & 0.39 & 0.22 & 3.47 & 0.03 & 0.01 \\
\hline 14 & 580.6 & 3.71 & 1.85 & 49.43 & 1.03 & 0.51 & 3.51 & 0.07 & 0.03 \\
\hline 15 & 596.6 & 6.16 & 3.56 & 49.79 & 0.85 & 0.49 & 3.61 & 0.05 & 0.03 \\
\hline 16 & 606.2 & 5.16 & 2.98 & 50.53 & 0.05 & 0.03 & 3.51 & 0.14 & 0.08 \\
\hline 17 & 624.8 & 3.81 & 1.90 & 50.41 & 0.12 & 0.06 & 3.64 & 0.04 & 0.02 \\
\hline 18 & 628.9 & 1.62 & 1.15 & 50.55 & 0.06 & 0.04 & 3.66 & 0.01 & 0.01 \\
\hline 19 & 625.9 & 1.67 & 0.96 & 50.39 & 0.14 & 0.08 & 3.71 & 0.06 & 0.03 \\
\hline 20 & 627.7 & 2.44 & 1.22 & 51.25 & 1.23 & 0.61 & 3.72 & 0.04 & 0.02 \\
\hline 21 & 633.8 & 0.72 & 0.41 & 53.37 & 0.77 & 0.44 & 3.77 & 0.03 & 0.02 \\
\hline
\end{tabular}


For male rats, the following allometric equations were found: $\mathrm{TL}=0.002193 . \mathrm{BM}+2.234$ and $\mathrm{MTL}=4.4629 . \mathrm{MC}^{0.3826}$. For female rats, the allometric equations were: $\mathrm{MTL}=3.6006$. $\mathrm{BM}^{0.4316}$ and $\mathrm{TL}=0.00304 \mathrm{BM}+2.132(\mathrm{BM}=$ body mass; $\mathrm{MTL}=$ muzzle-tail length; $\mathrm{TL}=$ tibia length).
Spearman's rank correlation coefficient was used for the results obtained using the equations and actual measured value in order to check for equation reliability. The coefficient was positive for the studied variables $(\mathrm{R}>-1)$. Males: MTL $(\mathrm{r}=0.93)$ and TL $(\mathrm{R}=0.96)$; females: MTL $(\mathrm{R}=0.92)$ and $\mathrm{TL}(\mathrm{R}=0.91)$.

TABLE 2 - Mean body mass (BM), muzzle - tail length (MTL), and tibia length (TL), with respective errors (SEM) and standard deviations (SD) of female Wistar rats according to the post-natal age.

\begin{tabular}{cccccccccc}
\hline Age (weeks) & \multicolumn{3}{c}{ BM $(\mathrm{g})$} & \multicolumn{3}{c}{ MTL $(\mathrm{cm})$} & \multicolumn{3}{c}{ TL $(\mathrm{cm})$} \\
\hline 3 & Mean) & SD & SEM & Mean & SD & SEM & Mean & SD & SEM \\
4 & 73.38 & 15.12 & 6.17 & 22.64 & 1.95 & 0.79 & 2.40 & 0.10 & 0.04 \\
5 & 125.4 & 12.59 & 5.14 & 28.76 & 1.66 & 0.68 & 2.68 & 0.13 & 0.05 \\
6 & 175.1 & 16.52 & 6.24 & 33.76 & 1.36 & 0.51 & 2.85 & 0.03 & 0.01 \\
7 & 220.8 & 11.68 & 5.22 & 37.48 & 1.53 & 0.68 & 2.89 & 0.04 & 0.01 \\
8 & 259.7 & 15.96 & 7.13 & 40.16 & 0.75 & 0.33 & 2.84 & 0.06 & 0.02 \\
9 & 298.7 & 27.11 & 11.07 & 42.36 & 1.48 & 0.60 & 2.91 & 0.05 & 0.02 \\
10 & 343.5 & 4.05 & 2.34 & 45.85 & 0.37 & 0.21 & 3.18 & 0.06 & 0.03 \\
11 & 355.8 & 3.63 & 1.81 & 47.22 & 0.51 & 0.25 & 3.23 & 0.08 & 0.04 \\
12 & 364.2 & 2.60 & 1.50 & 45.82 & 0.33 & 0.19 & 3.08 & 0.03 & 0.02 \\
13 & 372.3 & 3.10 & 1.55 & 46.89 & 0.52 & 0.26 & 3.18 & 0.07 & 0.03 \\
14 & 378.6 & 2.97 & 1.71 & 46.19 & 0.22 & 0.13 & 3.32 & 0.07 & 0.04 \\
15 & 384.8 & 1.31 & 0.65 & 46.21 & 0.25 & 0.12 & 3.496 & 0.05 & 0.02 \\
16 & 389.8 & 1.66 & 0.96 & 46.84 & 0.17 & 0.10 & 3.53 & 0.05 & 0.02 \\
17 & 395.9 & 2.27 & 1.31 & 47.34 & 0.62 & 0.35 & 3.49 & 0.01 & 0.006 \\
18 & 404.5 & 0.64 & 0.32 & 45.46 & 0.26 & 0.13 & 3.50 & 0.003 & 0.001 \\
19 & 402.2 & 0.29 & 0.21 & 47.38 & 0.24 & 0.17 & 3.52 & 0.001 & 0.001 \\
20 & 403.8 & 0.97 & 0.56 & 46.90 & 0.53 & 0.30 & 3.53 & 0.05 & 0.03 \\
21 & 406.3 & 3.06 & 1.53 & 47.12 & 0.81 & 0.40 & 3.49 & 0.01 & 0.005 \\
& 411.7 & 1.44 & 0.83 & 48.23 & 0.33 & 0.19 & 3.50 & 0.003 & 0.002 \\
\hline
\end{tabular}

Figure 1 shows the relationship between age and body mass increase for male and female rats, and Figure 2 presents the allometric relationships for the studied parameters. The final body mass was $633 \mathrm{~g}$ for males and $411 \mathrm{~g}$ for females. For MTL, the logarithmic plots presented a comparable display for males and females showing one ascending straight line with a marked inflection point corresponding to a BM of $351 \mathrm{~g}$ (MT length of 435 $\mathrm{mm}$ ) for males and $405 \mathrm{~g}$ for females (MT length of $462 \mathrm{~mm}$ ). The final MT length was $533 \mathrm{~mm}$ for males and $482 \mathrm{~mm}$ for females (21 weeks of age)

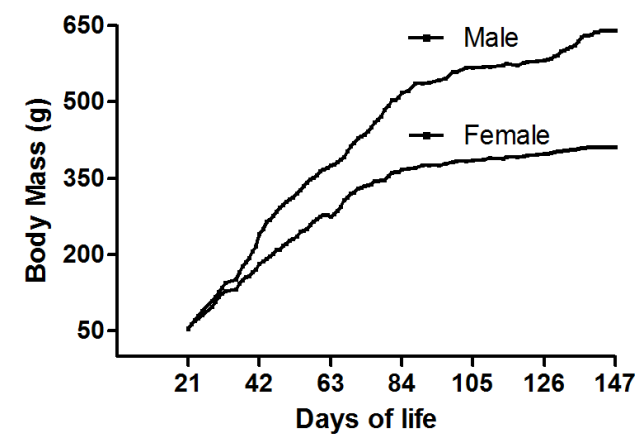

FIGURE 1 - Male and female Wistar rat curves for body mass and age. 


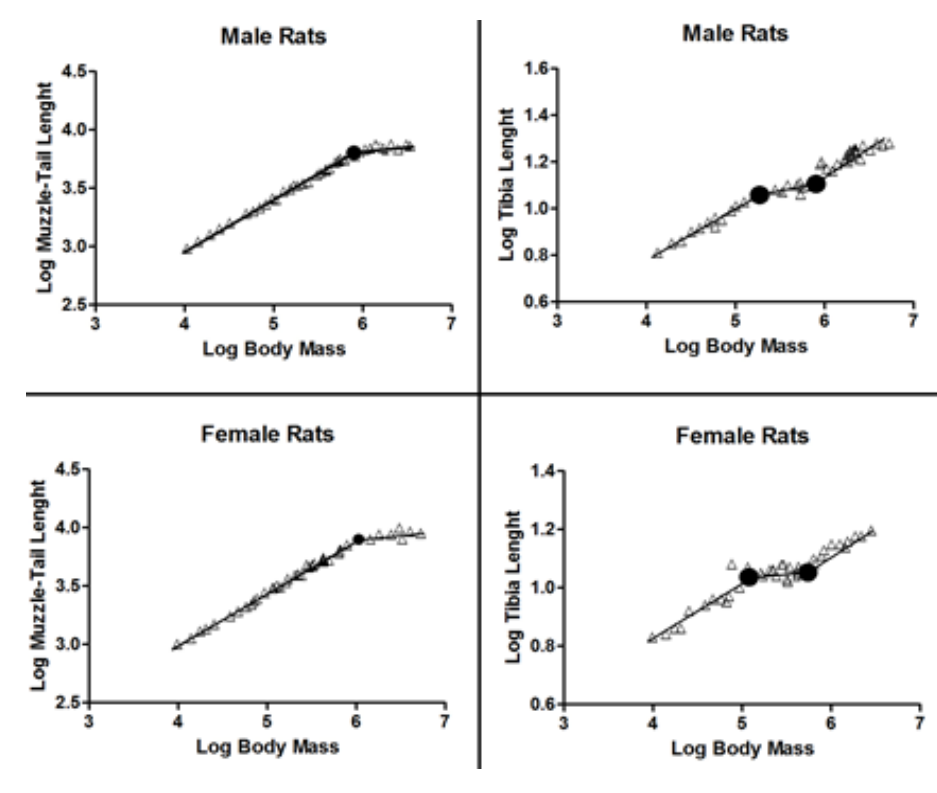

FIGURE 2 - Double logarithmic plots for body mass vs. muzzle-tail distance and body mass vs. tibia length from male and female Wistar rats.

For tibia growth, the curves for both genders were comparable and presented two inflexion points, thus denoting three different growth speeds. The first inflexion point occurred at the body weight of $185 \mathrm{~g}$ (length of $290 \mathrm{~mm}$; seven weeks of age) for males and at $182 \mathrm{~g}$ (length of $284 \mathrm{~mm}$; five weeks of age) for females. The second turning point occurred at $412 \mathrm{~g}$ (length of 322 $\mathrm{mm}$; nine weeks of age) for males and $334 \mathrm{~g}$ (length of $294 \mathrm{~cm}$; eight weeks of age) for females. The final TL for males was 377 $\mathrm{mm}$ and $350 \mathrm{~mm}$ for females (21 weeks of age).

\section{Discussion}

Since ancient Greece, mathematicians have been fascinated by a ratio named golden or divine, which is represented by a real constant with an approximate value of 1.618 designated by $\Phi$ (Phi). The ratio was named after the sculptor Phideas, who used it to build the Parthenon. In 1202, this constant was used by Fibonacci to describe rabbit population growth ${ }^{8}$. However, the numerical sequence had been described by Indian and Arabic mathematicians a few centuries earlier. Leonardo da Vinci may have used it to design the Vitruvian Man as well as the proportions for the Mona Lisa. Currently, the Fibonacci sequence is used in different fields such as philosophy, architecture, biology, computer science, physics $^{8}$, paleontology, and music.

In Biology, the study of growth regularities can be applied for both embryonic and post-natal development, tissue regeneration, and even carcinogenesis ${ }^{9}$. Empirically, as the whole size varies, the dimensions of some body parts of several species often appear to be related to each other by a power law called the allometric equation ${ }^{2}$. Therefore, allometry is a mathematical approach that transforms a relationship between body parts and organs by double-plotting the logarithms of two variables ${ }^{10}$. Frequently, one of the variables is easily obtained, such as BM, and the other variable can be obtained on the basis of the curves. Therefore, allometry quantitatively stands for the part/whole ratio ${ }^{1}$.

The advantages of allometric analysis is that growth kinetics represented by exponential and sigmoid curves may be transformed in a straight line and simply analyzed using linear techniques. However, some allometric relationships are more complex and cannot be represented by a straight line, as they require more refined mathematical methods ${ }^{2}$. In addition, the equations must be accompanied by statistical analysis to verify and validate the method used.

The preference for allometric models in a pilot study for an experimental research is encouraged by guide books for the handling and care of laboratory animals; the books provide subsidies to sample size calculation and ensure uniformity and standardization during project execution ${ }^{4}$. This policy reinforces the principle of three Rs (reduction, refinement, and replacement). This principle provides reduction in the number of animals used in each experiment, refinement of techniques to avoid unnecessary pain and suffering, and replacement by alternate methods such as mathematical models ${ }^{11}$.

Our data were collected from litters that resulted from a temporary polygamous system, i.e., with isolation of the female rat after pregnancy assumption. This procedure is recommended for rat reproduction because it maintains animal welfare, respects female physiology, allows matrices to rest during pregnancy and lactation, and decreases maternal and offspring mortality ${ }^{5}$. Wistar rats deliver 8 to 14 pups per litter, and each newborn pup has a BM between $5.5 \mathrm{~g}$ and $7 \mathrm{~g}^{12}$. Our results are in accordance with such figures, with an average of 11 pups per litter and $6.5 \mathrm{~g}$ of body weight per pup.

Our results showed that $\mathrm{BM}$ vs. length and BM vs. length of the tibia displayed a simple allometric pattern represented by straight lines with very definite turning points that depicted changes in growth rates. Further, we found a direct correlation between $\mathrm{BM}$ and another important parameter of maturity, which is animal length, expressed by the muzzle-tail distance. The allometric analysis showed that these two parameters maintain constant growth until $352 \mathrm{~g}$ for males and $631 \mathrm{~g}$ for females. Then, the rats stopped growing in length but continued to gain mass, and the allometric relationships were no longer valid. 
For relative growth between the tibia and BM, allometry showed three different speeds of growth with an initial rapid increase of TL followed by a plateau with very low growth and new acceleration of the growth speed. The final tibia curve represents the growth spurt before maturity. As expected, female rats matured earlier than their male counterparts. The aspects of tibia development are important in experimental orthopedic research that involve growth, as it allows the selection of the best age according to research purposes ${ }^{12}$. In addition, our findings are important when biomechanics of the bone limbs are used as a method of investigation because extrinsic biophysical processes module skeletal morphogenesis ${ }^{13,14}$, which means that heavier animals may have stronger bones. Changes in growth rates correspond to animal-specific development and maturation stages as well as correspond to rat puberty/sexual maturity in the final stage $^{5}$.

\section{Conclusions}

In Wistar rats, the relationship between body mass and animal length and tibia length showed that male and female animals displayed comparable allometric curves but female animals matured earlier. The animal longitudinal growth occurred in a single stage. In contrast, tibia length showed two stages of accelerated growth with an intermediate period of deceleration.

\section{References}

1 - Stevens CF. Darwin and Huxley revisited: the origin of allometry. J Biol. 2009;8(2):14. doi: 10.1186/jbiol119.

2 - Nijhout HF. Dependence of morphometric allometries on the growth kinetics of body parts. J Theor Biol. 2011;288:35-43. PMID: 21864540 .

3 - Arab HA, Muhammadnejad S, Naeimi S, Arab A. Allometric scaling relationship between frequency of intestinal contraction and body size in rodents and rabbits. J Biosci. 2013;38(2):391-5. PMID: 23660674.

4 - Festing MF, Altman DG. Guidelines for the design and statistical analysis of experiments using laboratory animals. ILAR 2002;43(4):244-58. doi: 10.1093/ilar.43.4.244.

5- Mattaraia VGM, Moura ASAM. Produtividade de ratos em diferentes sistemas de acasalamento. Cienc Rural. 2012;42(8):1490-6. doi: 10.1590/S0103-84782012000800026.

6 - Falcai MJ, Zamarioli A, Okubo R, de Paula FJ, Volpon JB. The osteogenic effects of swimming, jumping, and vibration on the protection of bone quality from disuse bone loss. Scand J Med Sci Sports. 2015;25(3):390-7. PMID: 24779886.

7 - Guide for the Care and Use of Laboratory Animals. National Research Council of the National Academies (ed.). 8ed. Washington DC: National Academy of Sciences; 2011.

8- Stakhov A. The golden section and modern harmony mathematics. In: Bergun GE, Philippov A, Horadan AF (ed.). Applications of fibonacci number. 1ed. New York: Springer Verlag; 1998. p.393-9.
9 - Martyushev LM1, Terentiev PS. A universal model of ontogenetic growth. Sci Nat. 2015;102:29-41. doi: 10.1007/s00114-015-1278-3.

10 - Gayon J. History of the concept of allometry. Am Zool. 2000;40(5):74858. doi: 10.1093/icb/40.5.748.

11 - Tannenbaum J, Bennett BT. Russell and Burch's 3Rs then and now: the need for clarity in definition and purpose. J Am Assoc Lab Anim Sci. 2015;54(2):120-32. PMID: 25836957.

12 - Mazeti, CM, Furlan MMDP. Crescimento e parâmetros reprodutivos de ratas Wistar, em restrição alimentar desde o nascimento. Acta Sci Biol Sci. 2008;(2):197-204. doi: 10.4025/actascibiolsci.v30i2.3623.

13 - van der Meulen MCH, Carter D. Developmental mechanics determine long bone allometry. J Theor Biol. 1995;172(4):323-7. PMID: 7715201.

14 - Brianza SZ, D’Amelio P, Pugno N, Delise M, Bignardi C, Isaia G. Allometric scaling and biomechanical behavior of the bone tissue: an experimental intraspecific investigation. Bone. 2007;40(6):163542. PMID: 17400044.

\section{Correspondence:}

Jose Batista Volpon

Laboratório de Bioengenharia, USP

Avenida Bandeirantes, 3900 14049-900 Ribeirão Preto - SP BrasilTel.: (55 16) 3315-3272/0225

hc.ortopedia@gmail.com

Received: July 13, 2015

Review: Sep 15, 2015

Accepted: Oct 19, 2015

Conflict of interest: none

Financial source: none

${ }^{1}$ Research performed at Laboratory of Bioengineering, Department of Biomechanics, Medicine and Rehabilitation, Faculty of Medicine of Ribeirao Preto, Universidade de São Paulo (USP), Ribeirao Preto-SP, Brazil. 